\title{
Endoscopic submucosal dissection for a symptomatic cervical esophageal cavernous hemangioma
}

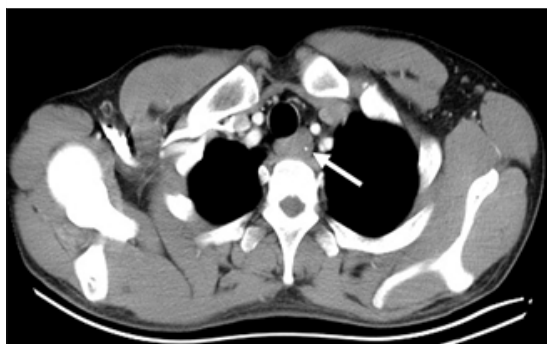

- Fig. 1 Chest computed tomography showed a mass convex to the esophageal lumen, causing stenosis, and enhanced gradually to show punctate calcification (white arrow).

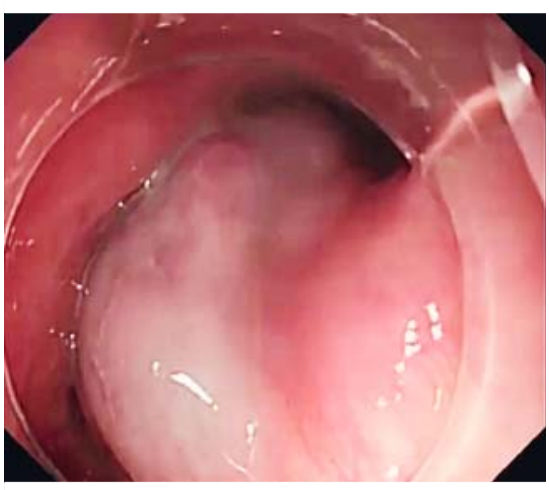

- Fig. 2 Gastroscopy revealed a mass with smooth bluish surface in the right posterior esophageal wall, $20 \mathrm{~cm}$ from the incisors.

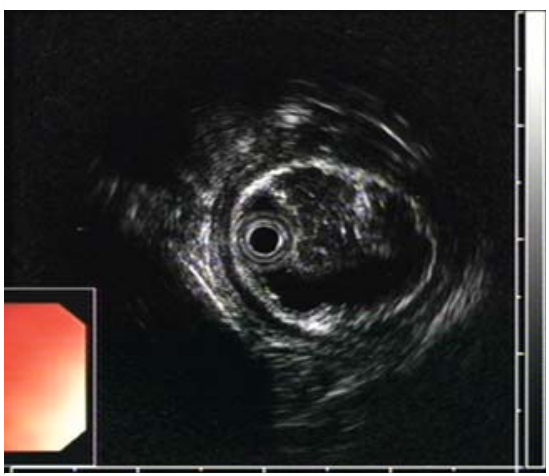

-Fig. 3 Endoscopic ultrasound showed an inhomogeneous hypoechoic and well demarcated mass localized to the submucosal layer and measuring $15 \mathrm{~mm} \times 20 \mathrm{~mm}$ in diameter.
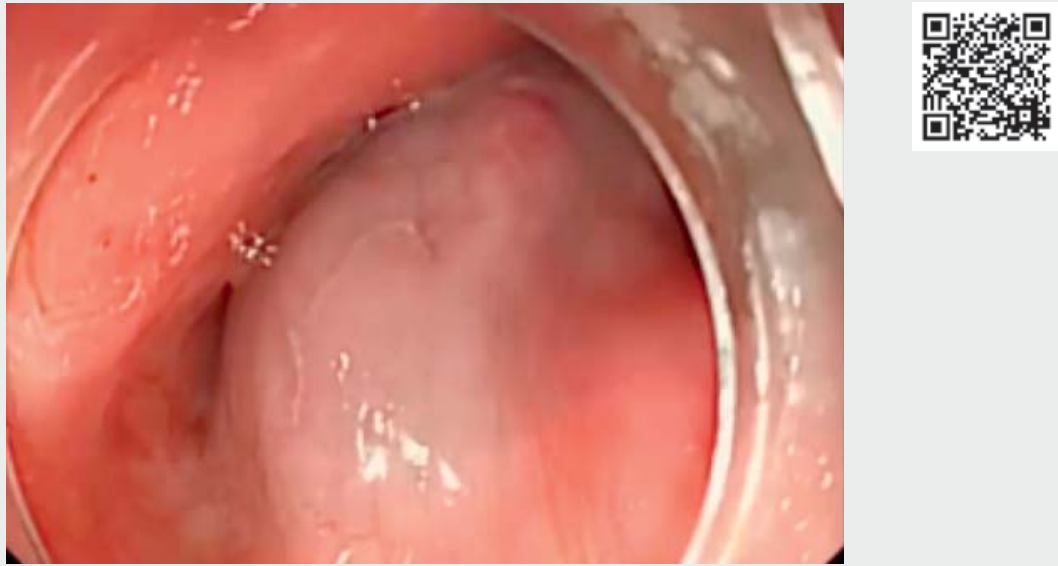

$\checkmark$ Video 1 The endoscopic submucosal dissection process was successful with minor bleeding during the procedure.
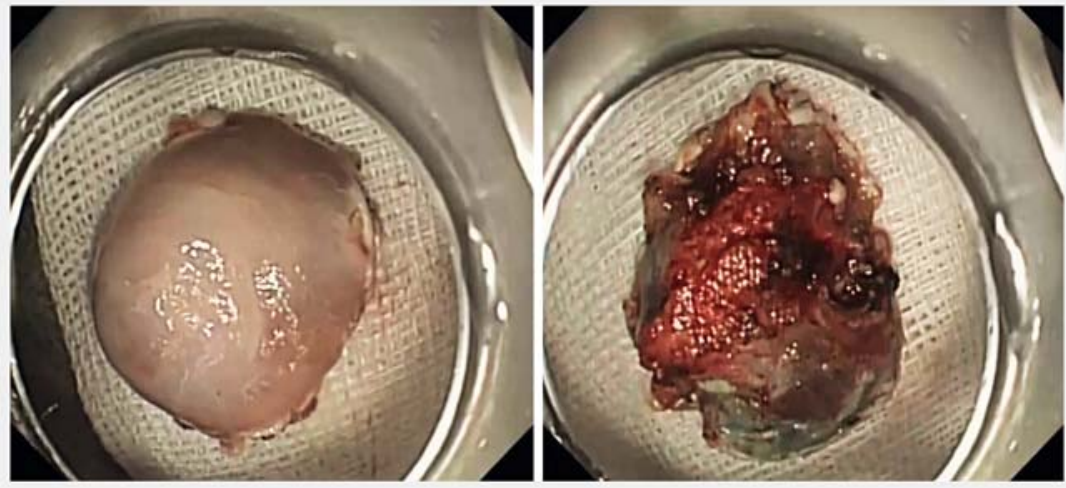

Fig. 4 The resected specimen contained a dark purple mass measuring $22 \mathrm{~mm} \times 22 \mathrm{~mm}$.

A 29-year-old man was found with a round mass in the cervical esophagus on chest computed tomography (CT) for dysphagia. The mass was convex to the esophageal lumen, causing stenosis, and enhanced gradually to show punctate calcification (white arrow) ( $>$ Fig. 1 ). Gastroscopy revealed a mass with a smooth bluish surface in the right posterior esophageal wall, $20 \mathrm{~cm}$ from the incisors

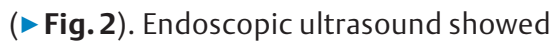
an inhomogeneous hypoechoic and well demarcated mass localized to the submucosal layer and measuring $15 \mathrm{~mm} \times$ $20 \mathrm{~mm}$ in diameter ( $\bullet$ Fig. 3 ).

Endoscopic submucosal dissection (ESD) was performed with the consent of the patient. The ESD process was successful with minor bleeding during submucosal dissection ( $\vee$ Video 1 ). The resected specimen contained a dark purple mass measuring $22 \mathrm{~mm} \times 22 \mathrm{~mm}$ ( $\triangleright$ Fig. 4). Histopathological results revealed proliferative vessels with a dilated lumen 


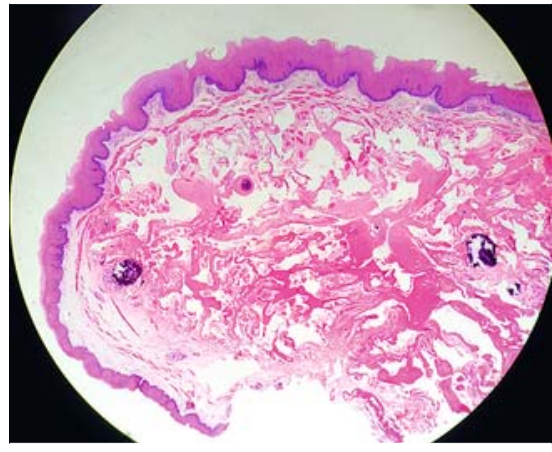

- Fig. 5 Histopathological results revealed proliferative vessels with dilated lumen covered by squamous epithelium in the submucosa, diagnosed as cavernous hemangioma.

covered by squamous epithelium in the submucosa, diagnosed as cavernous hemangioma ( $\mathbf{F i g . 5}$ ). The patient was discharged home uneventfully on postoperative day 4 . There were no symptoms observed at the 12-month follow-up.

Esophageal hemangiomas are extremely rare, representing only $3.3 \%$ of all benign esophageal tumors [1]. An esophageal hemangioma is usually asymptomatic; patients with additional symptoms such as hematemesis, melena, and dysphagia may require treatment. Esophagectomy, tumor enucleation, endoscopic sclerotherapy, laser therapy, and endoscopic mucosal resection have been reported to treat esophageal hemangioma [2]. However, because conventional endoscopic therapy cannot obtain specimens for pathological examination and is associated with a risk of residual or recurrent hemangioma, en bloc removal is another possible treatment option [3]. ESD is able to achieve en bloc margin-negative resection of tumors while avoiding invasive surgery and allowing preservation of the native organ [4]. Only a few reports showed that ESD may be applied for esophageal hemangiomas [3,5]. Herein, we presented a case of a symptomatic cervical esophageal cavernous hemangioma successfully removed en bloc by ESD. The benefits and risks of ESD in the treatment of esophageal hemangiomas need more investigation in the future.

\section{Endoscopy_UCTN_Code_TTT_1AO_2AG}

\section{Competing interests}

The authors declare that they have no conflict of interest.

The authors

Zhen Zhu ", Lu Wang ", Jian Yin, Li Zhang, Jun Liu, Lei Chen

Department of Gastroenterology, Clinical Medical College of Yangzhou University, Northern Jiangsu People's Hospital, Yangzhou, P.R. China

\section{Corresponding author}

\section{Lei Chen, MD}

Department of Gastroenterology, Clinical Medical College of Yangzhou University, Northern Jiangsu People's Hospital, No. 98, West Nantong Road, Yangzhou, Jiangsu Province, P. R. China, 225001

Fax: +86-0514-87373052

chenleidoctor@sina.com

\section{References}

[1] Plachta A. Benign tumors of the esophagus. Review of literature and report of 99 cases. Am J Gastroenterol 1962; 38: 639-652

[2] Rodrigues-Pinto E, Pereira P, Macedo G. Bluish discoloration of the esophagus: cavernous hemangioma of the pharynx and larynx with esophageal involvement. Endoscopy 2015; 47: E213-E214

[3] Kobara H, Mori H, Masaki T. Successful en bloc resection of an esophageal hemangioma by endoscopic submucosal dissection. Endoscopy 2012; 44: E134-E135

[4] Bhatt A, Abe S, Kumaravel A et al. Indications and techniques for endoscopic submucosal dissection. Am J Gastroenterol 2015; 110: 784-791

[5] Dawod Q, Issa D, Sharaiha RZ. Not all lesions are created equal: removal of a cavernous hemangioma. Endoscopy 2020; 52: E154E155

\section{Bibliography}

Endoscopy 2022; 54: E604-E605

DOI 10.1055/a-1694-3217

ISSN 0013-726X

published online 26.1.2022

(C) 2022. Thieme. All rights reserved.

Georg Thieme Verlag KG, Rüdigerstraße 14, 70469 Stuttgart, Germany

\section{ENDOSCOPY E-VIDEOS}

https:/|eref.thieme.de/e-videos

回席 Endoscopy E-Videos is an 靣制: open access online section, reporting on interesting cases and new techniques in gastroenterological endoscopy. All papers include a high quality video and all contributions are freely accessible online. Processing charges apply (currently EUR 375), discounts and wavers acc. to HINARI are available.

This section has its own submission website at https://mc.manuscriptcentral.com/e-videos

\footnotetext{
* The first two authors contributed equally to this work.
} 